\title{
Biochemistry and the Manufacture of Fine Chemicals
}

$\mathrm{I}^{\mathrm{N}}$ the Jubilee Memorial Lecture, 1933-1934, of the Society of Chemical Industry, delivered under the above title, Dr. F. H. Carr dealt chiefly with recent progress in the field of hormones and vitamins. In referring to the ill-defined boundary between biochemistry and organic chemistry, he classed as biochemical "those substances that exert dynamic properties in connexion with living processes and are directly concerned with chemical changes underlying physiological function". He characterised the technical production of insulin from the pancreas as one of the most important applications of biochemistry to the fine chemical industry, since countless human beings are kept alive by the use of this product. Insulin is a protein-like body of high molecular weight and unknown constitution, which enables the animal organism to deal with glucose; the total amount required daily by the human subject is about $5 \mathrm{mg}$. Only about $1 \mathrm{mg}$. per diem of thyreoglobulin, which occurs in the thyroid gland, is needed to promote the primary oxidative changes in the body. This complex protein owes its physiological properties to an iodine-containing derivative, thyroxine. The constitution of this substance is known, and it may be produced commercially at a cost lower than that of natural thyroxine. Adrenaline, another active hormone, which produces "all the vascular and visceral reactions accompanying the emotions of danger, excitement, and fright", has also been synthesised and subjected to successful large-scale manufacture.

Vitamin D (calciferol), of which about $0.05 \mathrm{mg}$. is required daily to promote the absorption of calcium and phosphate from the intestine into the blood, is formed when ultra-violet rays act upon ergosterol : "the pure vitamin can now be made and sold at such a price that our daily requirements cost less than one-tenth of a penny. Purchased as pure crystals, vitamin D now costs one-eighth its price in cod-liver oil". Vitamins A and D are fat-soluble substances found in the unsaponifiable fraction of certain fats. The recently synthesised vitamin C (ascorbic acid) is of a different type. It has been assigned the constitution 3-keto-l-gulonolactone, and is thus a remarkably simple substance having the formula $\mathrm{C}_{6} \mathrm{H}_{8} \mathrm{O}_{6}$. It is the first vitamin to be completely synthesised by the methods of organic chemistry.

Dr. Carr remarks that there was something of a mystical element in Szent-Györgyi's discovery of ascorbic acid. Having isolated it from adrenal glands, he overcame great difficulties in obtaining it from various plant materials : thus, in 1928, from 5,000 oranges he was successful in preparing only a very minute quantity. One evening in 1932, at Szeged, his wife gave him pepper for supper. This was the big red Hungarian capsicum. He could not eat it, but was impelled with his whole household to extract vitamin $\mathrm{C}$ from it-"with the result that after three weeks of hard labour we had a full pound of the pure crystalline ascorbic acid". This sudden production in large quantity of a substance previously only seen in microscopic amount led directly to the final elucidation of its constitution and its synthesis.

\section{Some Tunicates of the Terra Nova Expedition*}

$\mathrm{T}$ HE first portion of Prof. Garstang's long-promised account of the tunicates of the Terra Nova Expedition is now issued. This includes the Doliolida only, for each group is to be dealt with separately. It is not only a list and description of the species found, but also a critical monograph on the subject, containing valuable new views and a detailed survey of the work of previous writers, the whole being a helpful and important contribution to our knowledge of those pelagic tunicates which reproduce by budding and have 'nurse' stages.

No really new species are added but certain alterations in existing forms are made - one variety is raised to a species, a new genus is proposed, subgenera are raised to genera and the status of several species is reduced; the classification being completely revised. Every specimen has been examined, measured and recorded and the details summarised for each station separately. In the new classification proposed, the form and relations of the alimentary canal in gonozoid and phorozoid are taken as diagnostic ; also prominent features in the diagnosis of most species are the myomeristic growth-limits set up by the muscular rings, which are shown to act as obstacles to the forward extension of the branchial septum and testis during the late stages of growth. These limits depend on the period of meroblastic adhesions between inner and outer membranes, which may be accelerated or retarded by outside

* Report on the Tunicata. Part I. Doliolida. By Prof. Walter Garstang. British Antaretic (Terra Nova) Expedition, 1910. Natural History Report. Zoology. Vol. 4. No. 6. 1933. 'British Museum (Natural History). conditions such as temperature and food supply. Thus it is thought that many pairs of so-called species are in reality no more than environmental modifications.

In the chief work, which has been a study of the variation of certain characters in the common species and an attempt to discriminate between different kinds of 'old nurse', the measurements of the musclebands have proved very useful, especially in the latter. A very interesting fact is the distinction to be found in the otolith which usually drops away after death in the 'old nurses' of two species of Doliolina, but rarely in the third.

It is taken for granted that the ancestors of the Thaliacea were sessile primitive ascidians with a tailed larva and a metamorphic life-history, and that, of existing Thaliacea, the doliolids constitute the group most highly adapted to an active pelagic existence. The evidence in support of this view has been clearly set out in the author's earlier papers.

The specimens from the Terra Nova Expedition come from four different areas-Atlantic, Pacific, Southern Ocean and McMurdo Sound. Three genera are recognised (the fourth Dolioloides in the present classification not being represented). These are Doliolina, Dolioletta and Doliolum, two species in the first, two in the second and one in the third. The single species from the antarctic region proper, the $D$. resistabile of Neumann, here called Doliolum intermedium var. resistabile, was actually taken within the antarctic circle, further south than any doliolid so far recorded. 